\title{
Wideband centimetre range detector
}

\author{
$A$ Zikiy $^{1,}{ }^{*}, P$ Zlaman ${ }^{1}$, and $K$ Rumyantsev ${ }^{1}$ \\ ${ }^{1}$ Southern Federal University, Taganrog, Rostov Region, Russia
}

\begin{abstract}
An experimental study of the diode detector of the centimeter wavelength range has been carried out. A brief description of the circuit and design is given. The experiment was carried out on an installation containing a standard signal generator, a digital oscilloscope, a power supply, and a offset panel. The results of the experiment are the amplitude and amplitudefrequency characteristics of the detector. The following parameters have been shown to be achieved: operating frequency range of at least $8-18 \mathrm{GHz}$, voltage sensitivity of at least $100 \mu \mathrm{V} / \mu \mathrm{W}$, dynamic range of input signals at least $35 \mathrm{~dB}$, voltage sensitivity unevenness of no more than $1.6 \mathrm{~dB}$.
\end{abstract}

\section{Introduction}

Microwave detectors are widely used in transmitting, receiving and measuring equipment. There are numerous publications on microwave detectors, including monographs [1,2], tutorials [3], articles [4-6], patents [7], advertisements [8], however, the increased requirements for microwave detectors stimulates further research. The purpose of this work is an experimental study of a wideband centimeter range detector. The object of research is a microstrip detector with a frequency overlap of more than an octave and a complex matching circuit at the input. Previously, a similar detector was investigated in $[2,6]$, but in them the upper cutoff frequency does not exceed $10 \mathrm{GHz}$.

The following requirements are imposed on the detector:

- operating frequency range from 8 to $18 \mathrm{GHz}$;

- voltage sensitivity with a load resistance of $15 \mathrm{k} \Omega$ and an input power of $0.1-2 \mathrm{~mW}$ should be at least $100 \mu \mathrm{V} / \mu \mathrm{W}$;

- the dynamic range of input signals is not less than $35 \mathrm{~dB}$;

- the polarity of the output signal is negative;

- input resistance $50 \mathrm{Ohm}$;

- load resistance $2 \mathrm{kOhm}$.

\section{Diagram and design}

The scheme of the investigated detector is shown in figure $1[1,2,9,10]$. Resistors R1-R3, inductive elements L1, L2 ensure the matching of the diode with the microstrip line. Capacitor $\mathrm{C} 1$ and resistor R4 are elements of the low-pass filter [9, 10]. Structurally, the detector is a rectangular cup-type body made of brass. On one end of the body there is a

\footnotetext{
*Corresponding author: zikiy50@mail.ru
} 
connector X1 of type IX according to GOST13317, on the other end there is a glass isolator through which the output signal is output. A photo of the detector is shown in figure 2. A polycor board with sprayed and soldered elements L1, L2, R1-R4, VD1 is installed inside the case. The body is closed from above with a sealed cover.

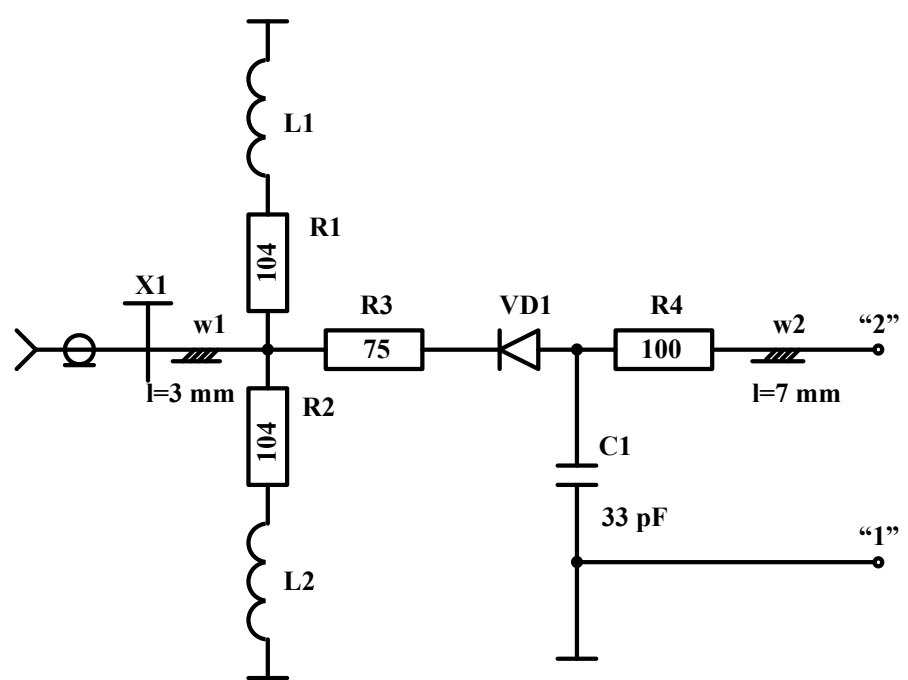

Fig. 1. Detector schematic diagram.

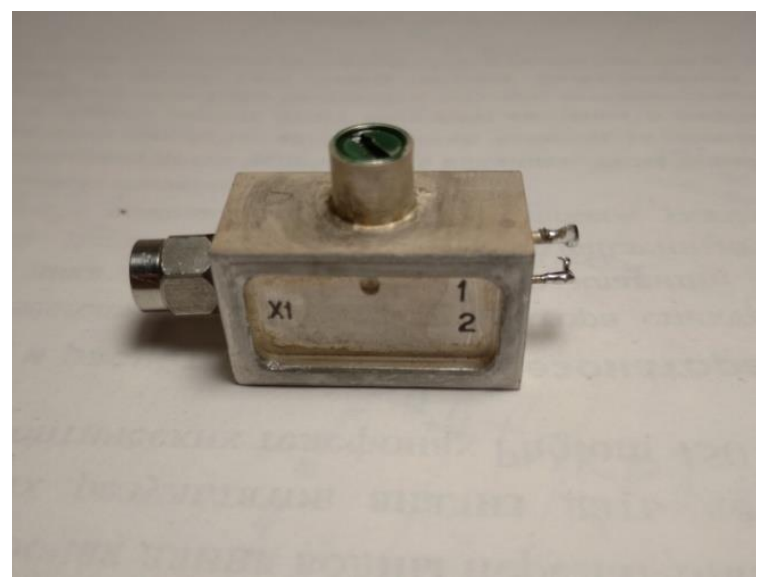

Fig. 2. Detector photo.

\section{Experiment}

The experiment was carried out on an installation, the block diagram of which is shown in figure 3 . The offset panel is used to set a fixed load value. 


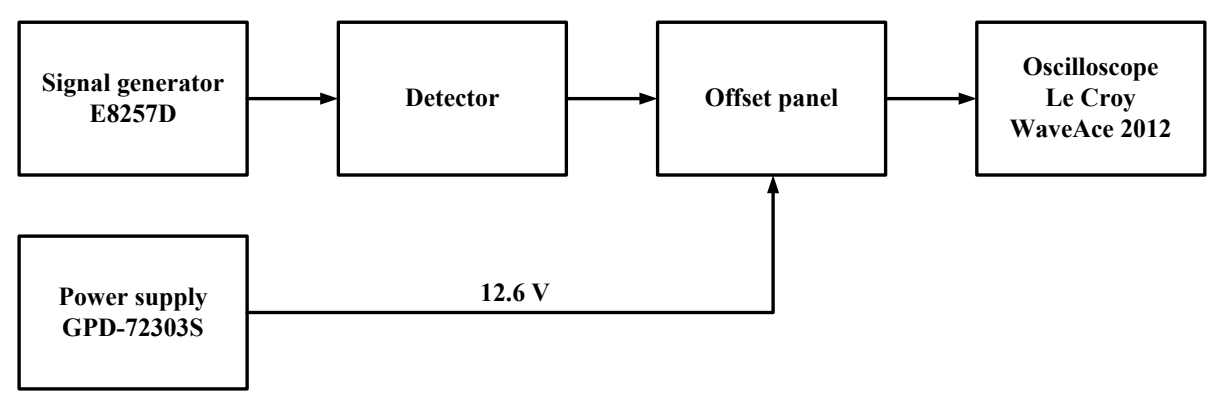

Fig. 3. Detector photo.

In the first experiment, the amplitude-frequency response of the detector was measured at an input signal power of minus $10 \mathrm{dBm}$. The generator was tuned in the frequency range from 8 to $18 \mathrm{GHz}$ with a step of $0.2 \mathrm{GHz}$. The results of measuring the output voltage (peak-topeak) were recorded in table 1 . According to table 1 , a diagram is built in figure 4 . It can be seen that the unevenness of the voltage sensitivity is $1.6 \mathrm{~dB}$. In the second experiment, the amplitude characteristics of the detector were measured at two frequencies, namely $8 \mathrm{GHz}$ and $18 \mathrm{GHz}$. The measurement results were recorded in table 2. According to table 2, the diagram are plotted in figure 5. These diagrams show that there is no explicitly quadratic detection area.

Table 1. Amplitude-frequency characteristic. $\left(i_{\mathrm{o}}=50 \mu \mathrm{A} ; \mathrm{P}_{\mathrm{in}}=-10 \mathrm{dBm} ; \tau_{\mathrm{i}}=100 \mu \mathrm{s} ; \mathrm{T}_{\mathrm{r}}=1 \mathrm{~ms} ; \mathrm{R}_{\mathrm{l}}=2\right.$ $\mathrm{k} \Omega)$.

\begin{tabular}{|c|c|c|c|}
\hline $\begin{array}{c}\text { Frequency } \\
\text { (GHz) }\end{array}$ & Amplitude (mV) & Frequency (GHz) & $\begin{array}{c}\text { Amplitude } \\
(\mathrm{mV})\end{array}$ \\
\hline 8.0 & 17 & 13.2 & 16 \\
\hline 8.2 & 17 & 13.4 & 16 \\
\hline 8.4 & 17 & 13.6 & 16.5 \\
\hline 8.6 & $16.5-17$ & 13.8 & 16 \\
\hline 8.8 & 16.5 & 14.0 & 16 \\
\hline 9.0 & 16.5 & 14.2 & 16 \\
\hline 9.2 & 16.5 & 14.4 & 16 \\
\hline 9.4 & 16.5 & 14.6 & 15 \\
\hline 9.6 & 16.5 & 14.8 & 15 \\
\hline 9.8 & 16.5 & 15.0 & 16 \\
\hline 10.0 & 16.5 & 15.2 & 16.5 \\
\hline 10.2 & 16.5 & 15.4 & 17 \\
\hline 10.4 & 16.5 & 15.6 & 17 \\
\hline 10.6 & 16.5 & 15.8 & 17.5 \\
\hline 10.8 & 16.5 & 16.0 & 18 \\
\hline 11.0 & 16.5 & 16.2 & 18 \\
\hline 11.2 & 16.5 & 16.4 & 18 \\
\hline 11.4 & 16.5 & 16.6 & 18 \\
\hline 11.6 & 16.5 & 16.8 & 18 \\
\hline 11.8 & 16.5 & 17.0 & 18 \\
\hline 12.0 & 16.5 & 17.2 & 18 \\
\hline 12.2 & 16.5 & 17.4 & 18 \\
\hline 12.4 & 16.5 & 17.6 & 18 \\
\hline 12.6 & 16.5 & 17.8 & 18 \\
\hline 12.8 & 16.5 & 18.0 & 18 \\
\hline 13.0 & 16 & & \\
\hline
\end{tabular}


Table 2. Detector amplitude characteristic. $\left(\mathrm{i}_{\mathrm{o}}=50 \mu \mathrm{A} ; \mathrm{P}_{\mathrm{in}}=-10 \mathrm{dBm} ; \tau_{\mathrm{i}}=100 \mu \mathrm{s} ; \mathrm{T}_{\mathrm{r}}=1 \mathrm{~ms} ; \mathrm{R}_{\mathrm{l}}=2 \mathrm{k} \Omega\right)$.

\begin{tabular}{|c|c|c|c|c|}
\hline \multirow[t]{2}{*}{$P_{\text {in }} \cdot \mathrm{dBm}$} & \multicolumn{2}{|c|}{$\mathrm{f}=8.0 \mathrm{GHz} . \mathrm{R}_{\mathbf{l}}=2 \mathrm{k} \Omega$} & \multicolumn{2}{|c|}{$\mathrm{f}=18.0 . \mathrm{R}_{\mathrm{l}}=2 \mathrm{\kappa} \Omega$} \\
\hline & $\mathbf{U}_{\text {out. }} \mathbf{m V}$ & $\mathrm{U}_{\text {out. }} \mathbf{d B m V}$ & $\mathrm{U}_{\text {out }} \cdot \mathbf{m V}$ & $\mathrm{U}_{\text {out }} \mathrm{dBmV}$ \\
\hline-20 & 5 & 14.0 & 4.48 & 13.0 \\
\hline-18 & 6 & 15.6 & 5.44 & 14.7 \\
\hline-16 & 7 & 16.9 & 7.52 & 17.5 \\
\hline-14 & 8 & 18.0 & 8.2 & 18.3 \\
\hline-12 & 11.6 & 21.3 & 11.4 & 21.1 \\
\hline-10 & 16.0 & 24 & 16.0 & 24.1 \\
\hline-8 & 22 & 26.8 & 21.2 & 26.5 \\
\hline-6 & 32 & 30.1 & 30.4 & 29.6 \\
\hline-4 & 44 & 32.8 & 42.4 & 32.5 \\
\hline-2 & 60 & 35.6 & 58.4 & 35.3 \\
\hline 0 & 82 & 38.3 & 80 & 38.0 \\
\hline 2 & 110 & 40.8 & 107.2 & 40.6 \\
\hline 4 & 144 & 43.1 & 144 & 43.1 \\
\hline 6 & 192 & 45.7 & 192 & 45.6 \\
\hline 8 & 248 & 47.9 & 248 & 47.9 \\
\hline 10 & 320 & 50.1 & 336 & 50.5 \\
\hline 12 & 408 & 52.2 & 416 & 52.4 \\
\hline 14 & 516 & 54.2 & 528 & 54.4 \\
\hline 16 & 640 & 56.1 & 656 & 56.3 \\
\hline 18 & 808 & 58.1 & 800 & 58.0 \\
\hline 20 & 968 & 59.7 & 960 & 59.6 \\
\hline-20 & 6.56 & 16.3 & 7.2 & 17.1 \\
\hline-18 & 7.68 & 17.7 & 8.0 & 18.0 \\
\hline-16 & 10.24 & 20.2 & 10.48 & 20.4 \\
\hline-14 & 13.6 & 22.6 & 13.36 & 22.5 \\
\hline-12 & 16.24 & 24.2 & 18.0 & 25.8 \\
\hline-10 & 21.8 & 26.7 & 25.0 & 27.9 \\
\hline-8 & 31.6 & 30.0 & 36.0 & 31.1 \\
\hline-6 & 45.2 & 33.5 & 50.4 & 34.0 \\
\hline-4 & 62.0 & 35.8 & 72.0 & 37.1 \\
\hline-2 & 84.8 & 38.5 & 98.0 & 39.8 \\
\hline 0 & 115.0 & 41.2 & 132.0 & 42.4 \\
\hline 2 & 160.0 & 44.0 & 176.0 & 44.9 \\
\hline 4 & 208.0 & 46.3 & 234.0 & 47.3 \\
\hline 6 & 276.0 & 48.8 & 306.0 & 49.7 \\
\hline 8 & 356.0 & 51.0 & 408.0 & 52.2 \\
\hline 10 & 456.0 & 53.2 & 520.0 & 54.3 \\
\hline 12 & 576.0 & 55.2 & 648.0 & 56.2 \\
\hline 14 & 760.0 & 56.0 & 808.0 & 57.1 \\
\hline 16 & 940.0 & 57.6 & 981.0 & 58.1 \\
\hline 18 & 1140.0 & 61.1 & 1200.0 & 61.6 \\
\hline 20 & 1320.0 & 62.4 & 1426.0 & 63.0 \\
\hline
\end{tabular}




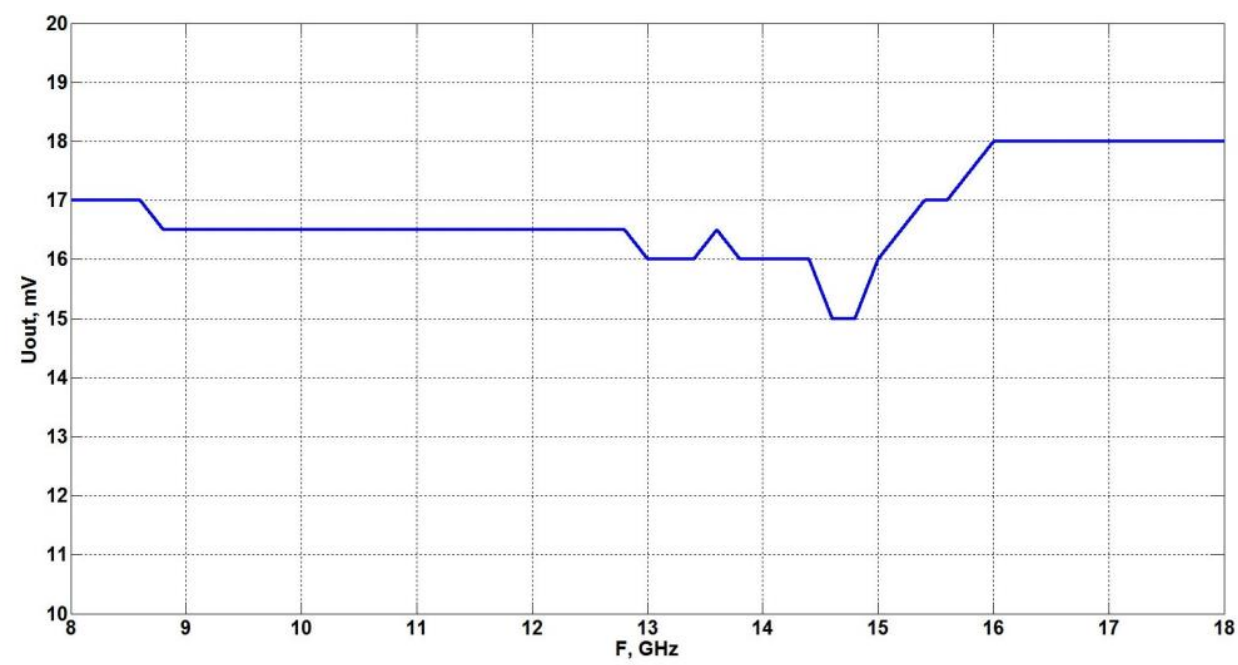

Fig. 4. Output voltage vs frequency.

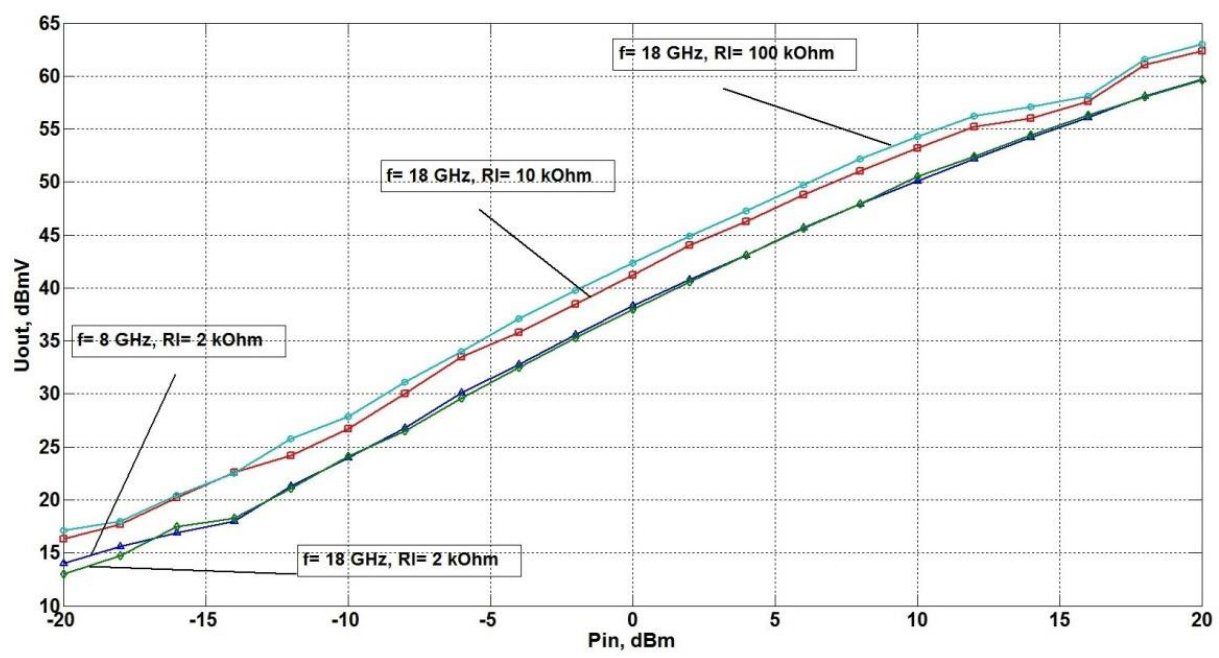

Fig. 5. Detector amplitude characteristics.

In the third experiment, the oscillograms were photographed at the detector output. In this case, the following signal parameters were set on the generator of standard signals: for figure 6 , the carrier frequency is $8.0 \mathrm{GHz}$, the power $P_{\text {in }}=-10 \mathrm{dBm}$, the duration is $100 \mu \mathrm{s}$, and the repetition period is $1 \mathrm{~ms}$. For figure 7, the signal parameters are set: carrier frequency 18.0 $\mathrm{GHz}$, power $\mathrm{P}_{\mathrm{in}}=0 \mathrm{dBm}$, duration $100 \mu \mathrm{s}$, repetition period $1 \mathrm{~ms}, \mathrm{R}_{\mathrm{l}}=100 \mathrm{k} \Omega$. 


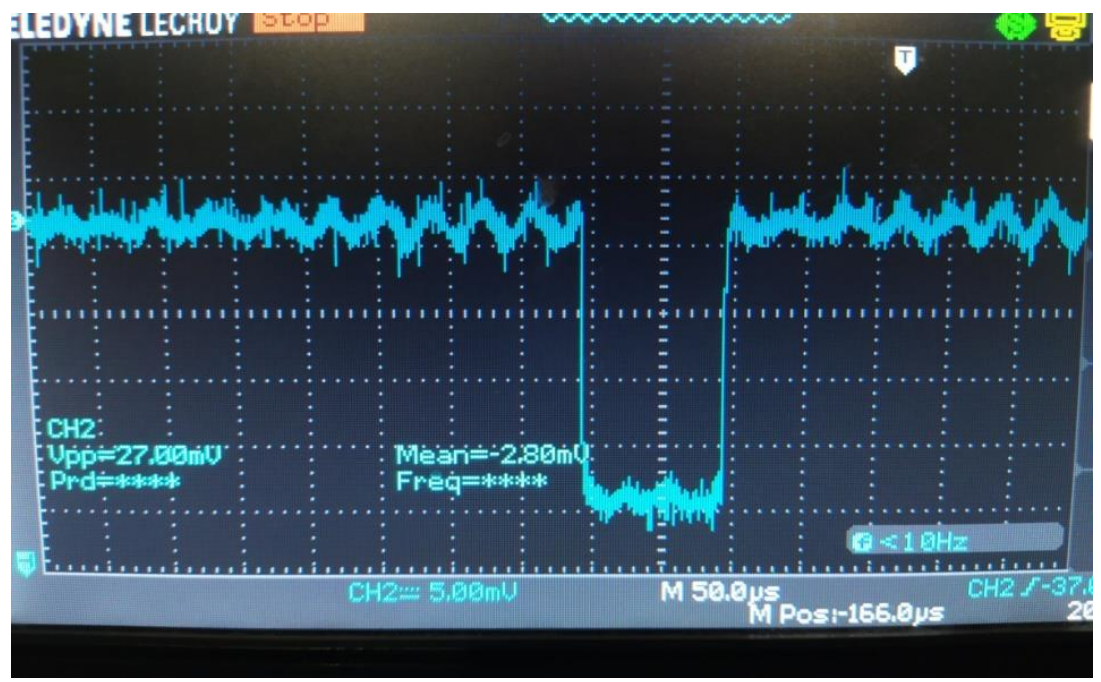

Fig. 6. Mixture of signal and noise at the detector output at $\mathrm{i}_{\mathrm{o}}=0 ; \mathrm{P}_{\mathrm{in}}=-10 \mathrm{dBm}$; $\tau_{\mathrm{i}}=100 \mu \mathrm{s} ; \mathrm{R}_{\mathrm{l}}=100 \mathrm{k} \Omega$.

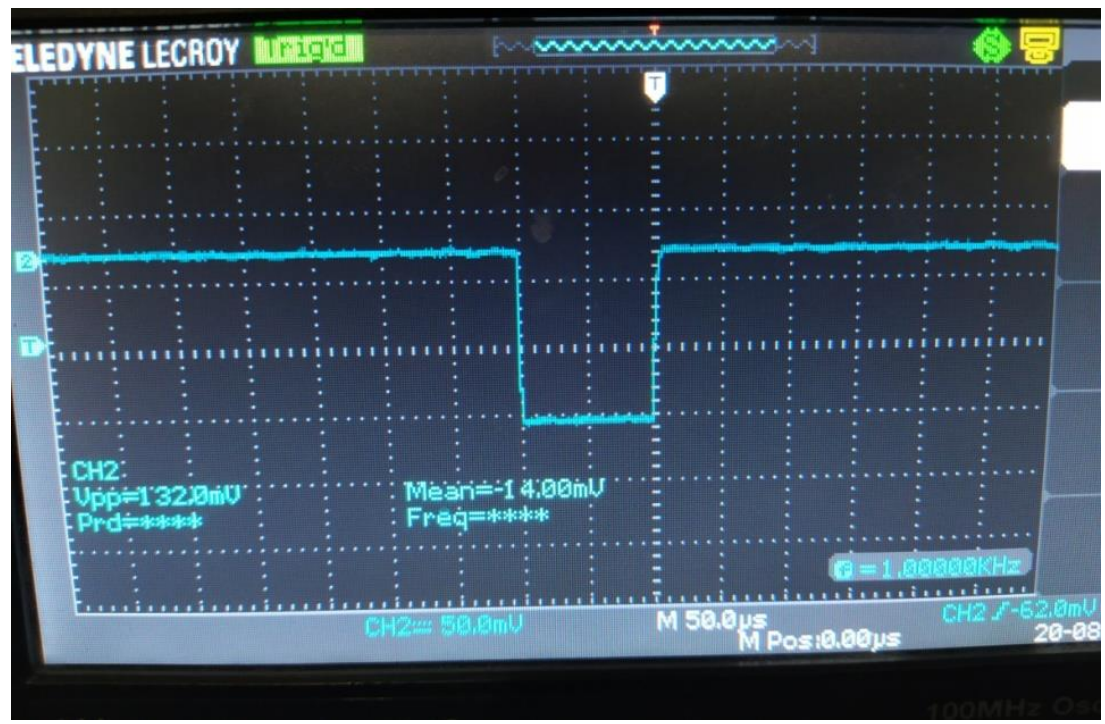

Fig. 7. Mixture of signal and noise at the detector output at $\mathrm{i}_{\mathrm{of}}=0 ; \mathrm{P}_{\mathrm{in}}=0 \mathrm{dBm}$; $\tau_{\mathrm{i}}=100 \mu \mathrm{s} ; \mathrm{R}_{\mathrm{l}}=100 \mathrm{k} \Omega$.

\section{Conclusions}

Table 3 below shows a comparison of the given and achieved parameters of the detector.

Table 3. Detector amplitude characteristic.

\begin{tabular}{|l|c|c|}
\hline \multicolumn{1}{|c|}{ Parameter name, dimension } & Given & Measured \\
\hline Operating frequency range, $\mathrm{GHz}$ & $8-18$ & $8-18$ \\
\hline $\begin{array}{l}\text { Voltage sensitivity with a load resistance of } 2 \mathrm{kOhm} \\
\text { and input powers of } 0.1-2 \mathrm{~mW}, \text { not less, } \mu \mathrm{V} / \mu \mathrm{W}\end{array}$ & 100 & $\begin{array}{c}150 \text { with } \mathrm{P}_{\text {in }}=0.1 \\
\mathrm{~mW}\end{array}$ \\
\hline Dynamic range of input signals, not less, $\mathrm{dB}$ & 35 & 40 \\
\hline
\end{tabular}




\begin{tabular}{|l|c|c|}
\hline Output signal polarity & negative & negative \\
\hline Input impedance, Ohm & 50 & 50 \\
\hline Load resistance, kOhm & 2 & $2 ; 10 ; 100$ \\
\hline Voltage sensitivity unevenness, dB & - & 1,6 \\
\hline
\end{tabular}

Table 3 shows that all the requirements for the detector are met.

\section{References}

[1] Kudryavtseva A A 2006 Microwave and EHF radio measuring equipment. Nodal and element base (Moscow: Radiotekhnika) p 208

[2] Silaev M A and Komov A N 1984 Measuring semiconductor microwave converters (Moscow: Radio and communication) p 152

[3] Pakhomov V V, Vechkanova R A, Galdina N M 1989 Semiconductor diode microwave devices (Kuibyshev: KuAI) p 96

[4] Butkov V P, Zikiy A N, Zlaman P N 2014 Electrical and data processing facilities and systems 2(10) 111-116

[5] Butkov V P, Gubarev D E, Zikiy A N, Zlaman P N 2017 Don's Engineering Bulletin 1 ivdon.ru/ru/magazine/archive/n1y2017/4032

[6] Pratt R E 1975 Hew Packard J 27(10) 8-10

[7] Zhdanov A B and Kozlova A S 1991 Microwave detectors (USSR author's certificate No. 1.646.043. Publ. B. I No. 16)

[8] 2002 Coaxial, waveguide and optical devices Catalog (Nizhny Novgorod Scientific Research Instrument Making Institute "Quartz") p 82

[9] Frequency synthesizer RF6-03 Technical description and instruction manual (EЭ2.206.521TO Album 1) p 398

[10] Frequency synthesizer RF6-03 Technical description and instruction manual (EЭ2.206.521TO Album 2) p 216 